\title{
DEVELOPMENT OF HOT TEARING EVALUATION METHOD FOR Al-BASED ALLOYS
}

\begin{abstract}
This paper focuses on developing an advanced test method and its use to study hot tearing defects in aluminium alloy castings. The paper consists of two parts. The first part introduces the reader to hot tearing in general, and provides theoretical analysis of the hot tearing phenomenon. The second part describes a newly developed method for assessing hot tearing susceptibility, and also gives the results on hot tearing for various aluminium alloys. During the test, the effect of alloy chemical composition on hot tearing susceptibility was analyzed. Three different Al-based alloys with varying $\mathrm{Si}, \mathrm{Cu}$ and $\mathrm{Ti}$ contents were examined. Conclusions deal with the effect of individual elements on hot tearing susceptibility, and confirm that the main objective was achieved and the proposed method proves to be repeatable and reliable.

Keywords: hot tearing, aluminium alloys, chemical composition, solidification interval
\end{abstract}

\section{Introduction}

Hot tears are integrity defects forming on a semi-solid alloy prior to its complete solidification. Generally, there are two main categories of factors responsible for hot tearing in castings: metallurgical factors and mechanical factors. The metallurgical aspects, such as alloy grain size and morphology of intermetallic phases, influence both the semi-solid mechanical properties (i.e. strength and ductility) of the alloy as well as the ability of the liquid metal to feed the solidifying alloy. Such factors are directly affected by the alloy's solidification characteristics. The mechanical factors, on the other hand, are due to the casting deformation caused by thermal contraction within a rigid steel mold. The rigidity of the mold restricts contraction of the casting during cooling, thereby inducing tensile strain and stress and promoting the formation of hot tears in the casting. The major hindrance in hot tearing analysis is the absence of a method to quantitatively measure the stress and strain causing hot tears in castings. In the case of the remaining factors (i.e. solidification and microstructure), numerous techniques are readily available for characterization [1,2].

Hot tearing is influenced by many factors. Previous studies have developed various theories to clarify the mechanism of hot tearing but there has been no consensus. Past conventional hot tearing tests have provided a qualitative index by measuring the cracks on the castings. It is more difficult to set up a quantitative experiment, and such a test is limited as to repeatability $[3,4]$.

The primary objective of this work is to design, optimize and manufacture a new simple and reliable methodology to analyze hot tearing in aluminium alloy castings, and further implement the experimental melts to investigate the impact of various factors on cracking.

The second objective is to investigate the hot tearing tendency of various aluminium alloys. The main goal will be to evaluate the effect of chemical composition on the hot tearing tendency.

\section{Experimental procedure}

The experimental section is divided into 3 parts: (1) measuring apparatus, (2) alloys, and (3) hot tearing index.

\subsection{Measuring apparatus}

The designed mold is constructed in order to support hot tearing development during solidification. It consists of four arms of different lengths, which are connected to the inlet channel. Every arm is anchored on both ends to support the shrinkage effect, which can ultimately results in hot tearing occurrence. Anchored arms will serve as a quantitative evaluation method of hot tearing. Besides anchored arms, the mold also contains one arm connected to a load cell measuring evolving strain. Another instrument for evaluating hot tearing is a refractory glass placed in the position where hot tearing has a high probability to occur. Use of the glass will allow observing hot tearing evolution in real time. Hot tearing will therefore be evaluated not only quantitatively but also qualitatively. The first draft is shown in Fig. 1a.

\footnotetext{
* DEPARTMENT OF TECHNOLOGICAL ENGINEERING, UNIVERSITY OF ŽILINA. UNIVERZITNÁ 8215/1, 01026 ŽILINA, SLOVAK REPUBLIC

* Corresponding author: Marek.Bruna@fstroj.uniza.sk
} 
After carrying out experimental casts we found out that the mold contains a few fundamental flaws that had to be removed. The first was the formation of a turbulent vortex in the gating system resulting in, inter alia, the lack of fluidity. The second problem was a massive weight, resulting in complicated handling during experimental casts. Based on these flaws, optimization was required.

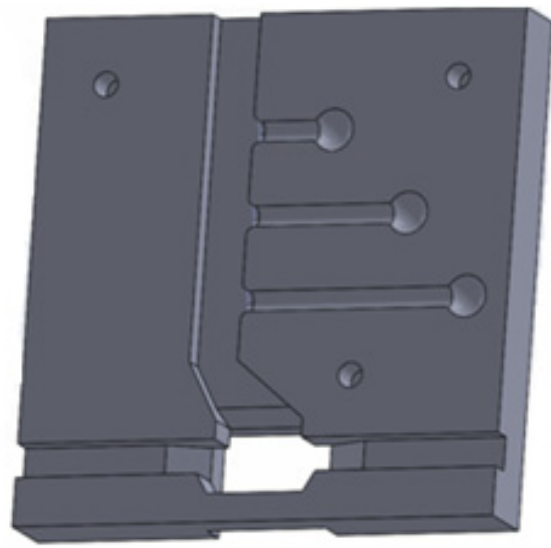

a)

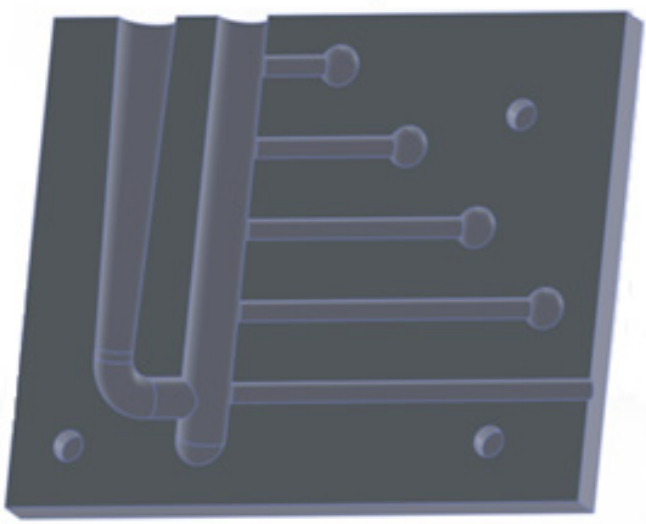

b)

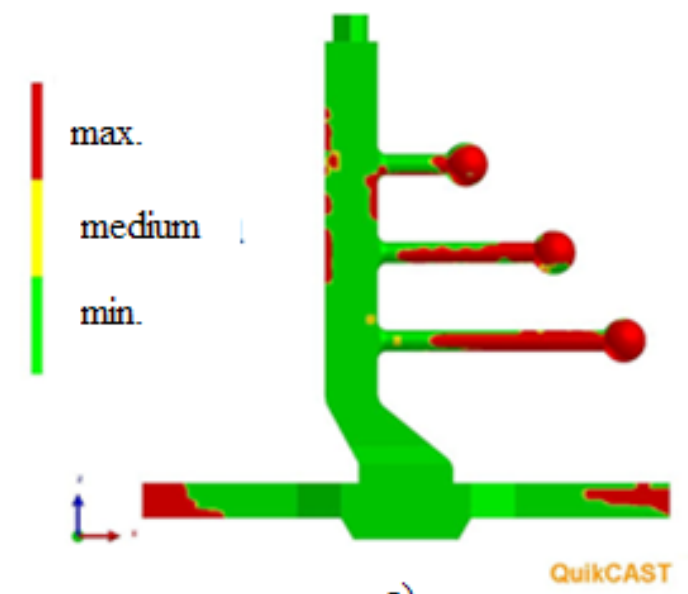

a)

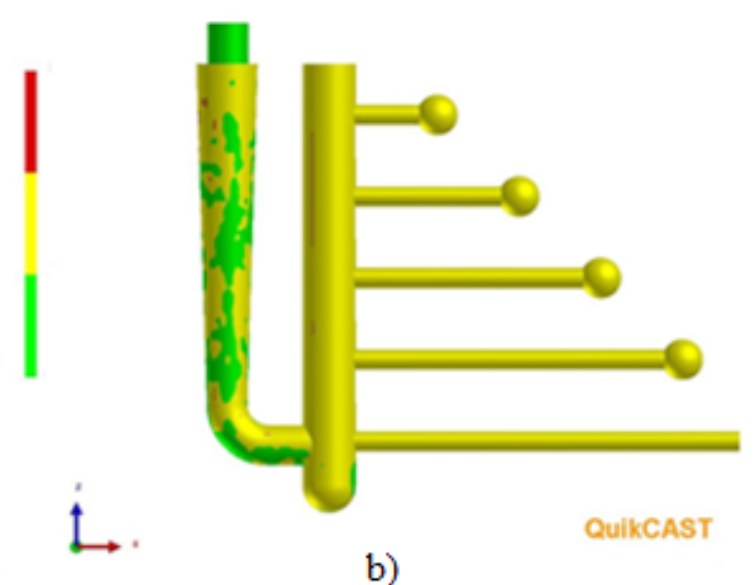

Fig. 2. Simulations: a) First design, b) Second design

Based on the previous findings, the final version of the optimal model was created (Fig. 3). Fluidity improved, and also a satisfying weight was achieved.
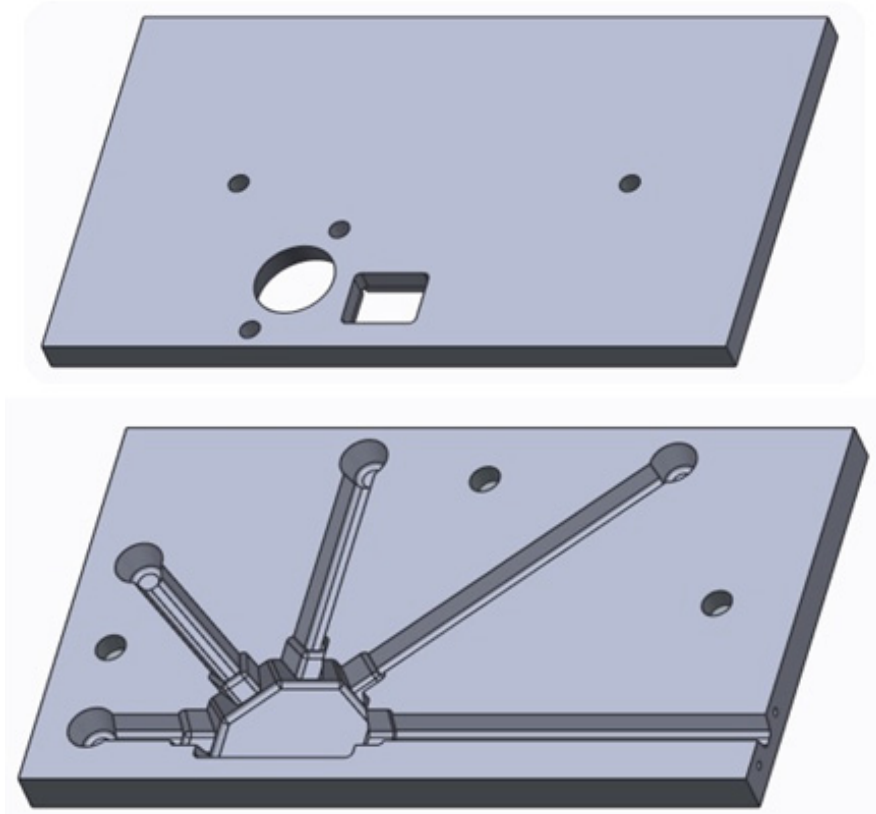

\section{Fig. 3. Final mold design}

Therefore, a new mold was created (Fig. 1b), which met the conditions for fluidity, yet still did not eliminate excess weight.

For the needs of optimization, CAD models of individual molds were subjected to simulations by QuikCAST software to determine the fluidity condition. Fig. $2 \mathrm{a}$ and Fig. $2 \mathrm{~b}$ shows the results of the simulations. The color reflects the level of the melt misrun possibility:

- Red - high risk,

- Yellow - moderate risk,

- Green - minimal risk.

In the first model we can see a high proportion of red, which represents a critical area for misrun occurrence. The area refers to grading arms for the needs of qualitative assessment.

After the first optimization (Fig. 2b), we can see a significant improvement. The gating system no longer contains red areas, but a significant proportion of yellow still represents a possible risk of poor melt flow into the mold cavity. 
Fig. 4 represents the simulation results of the final mold in terms of fluidity. Visualization shows the highest proportion of green, providing the best performance during casts. CAD models were created using SolidWorks and Creo2 (Pro / ENGINEER).

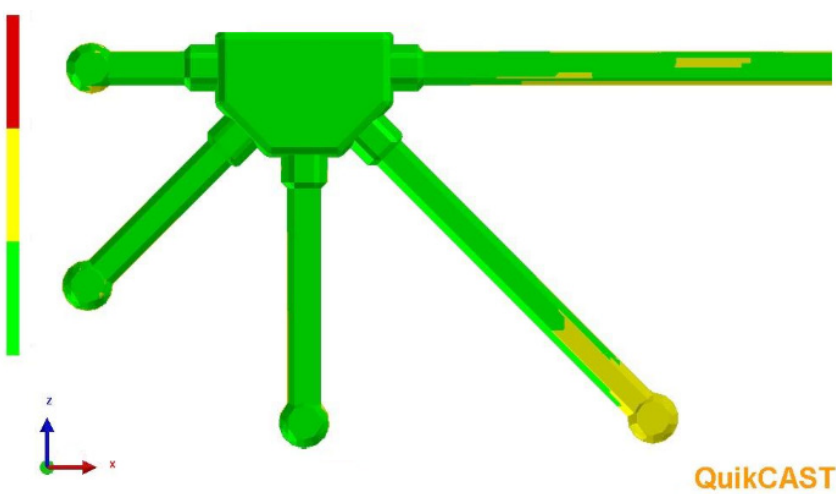

Fig. 4. Simulation of final model

Experimental casts were performed in dog bone shaped die mold preheated to $150 \pm 10^{\circ} \mathrm{C}$. Figure 5 shows instrumentation and installation of experimental system. As a load cell was used force sensor S9M by HBM Company. Data acquisition system was composed of NATIONAL INSTRUMENTS Hi-Speed USB Carrier NI USB - 9162 For K-type thermocouple and NATIONAL INSTRUMENTS NI USB - 6009 for force sensor. As bridge signal amplifier was used CLIP AE 301 with accuracy class 0.1 . Whole system was powered by VOLTCRAFT PS 303 Pro Laboratory Power Supply. In addition to hot tearing index evaluation described in this work, proposed apparatus is able to measure contraction forces and temperatures in real-time by using the data acquisition system. The measured data can be recorded for post processing to evaluate hot tearing formation and solidification stages. Die mold contains also refractory glass in the upper part, through which we will be able in future experiments observe hot tear formation in real time by highsensitive camera.

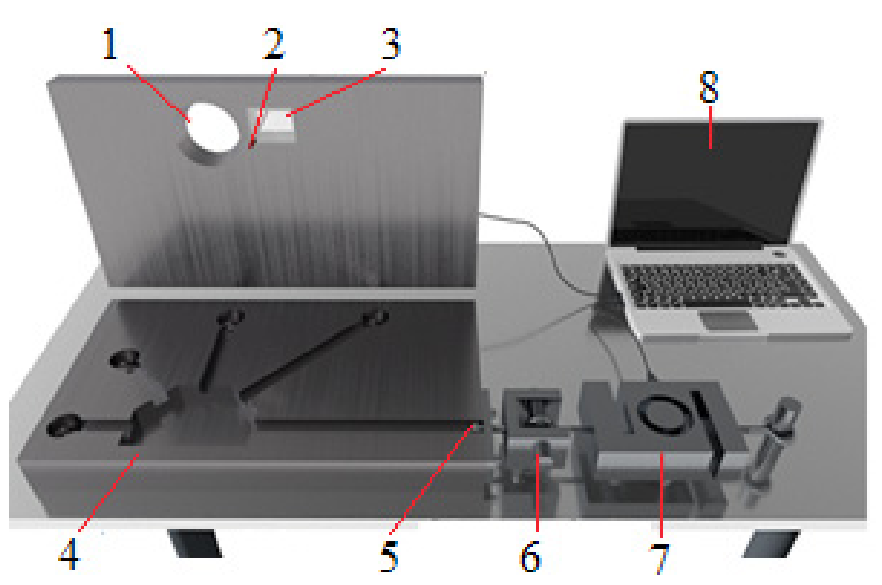

Fig. 5. Measuring apparatus ( 1 - Inlet, 2 - Thermocouple, 3 - Refractory glass, 4 - Mold, 5 - Anchoring screw, 6 - Gripping mechanism, 7 - Load cell, 8 - Data processing unit)

\subsection{Used alloys}

As the first we used aluminium alloy AlSi6Cu4, second alloy $\mathrm{AlCu} 4 \mathrm{Ti}$ and finally we analyzed alloy AlSi7Mg0.3. Table 1 shows the chemical composition of the analyzed alloys and the solidification intervals are shown (obtained from supplier material data sheets) in the Table 2.

TABLE 1

Chemical composition of used alloys

\begin{tabular}{|c|c|c|c|c|c|c|c|c|}
\hline \multirow{2}{*}{ Alloy } & \multicolumn{7}{|c|}{ Chemical composition [\%] } \\
\cline { 2 - 10 } & $\mathbf{S i}$ & $\mathbf{F e}$ & $\mathbf{C u}$ & $\mathbf{M n}$ & $\mathbf{M g}$ & $\mathbf{Z n}$ & $\mathbf{T i}$ & $\mathbf{N i}$ \\
\hline AlSi6Cu4 & 6.0 & 0.9 & 4.0 & 0.45 & 0.55 & 2.0 & 0.20 & 0.45 \\
\hline AlCu4Ti & 0.05 & 0.127 & 4.612 & 0.456 & 0.05 & - & 0.171 & 0.006 \\
\hline AlSi7Mg0.3 & 7.3 & 0.15 & 0.03 & 0.10 & 0.3 & 0.07 & 0.15 & - \\
\hline
\end{tabular}

TABLE 2

Solidification interval of used alloys

\begin{tabular}{|c|c|}
\hline Alloy & Solidification interval $\left[{ }^{\circ} \mathbf{C}\right]$ \\
\hline $\mathrm{AlSi} 6 \mathrm{Cu} 4$ & $620-490$ \\
\hline $\mathrm{AlCu} 4 \mathrm{Ti}$ & $640-480$ \\
\hline $\mathrm{A} 1 \mathrm{Si} 7 \mathrm{Mg} 0.3$ & $625-555$ \\
\hline
\end{tabular}

\subsection{Hot tearing index}

The evaluated criterion is "hot tears index" (HTI). This criterion is determined by the nature and amount of tears in the four arms of different lengths. We used each alloy to cast three samples. The samples were removed from the mold after five minutes for visual evaluation. The melt temperature was $720 \pm 5^{\circ} \mathrm{C}$, and the mold was preheated to $150 \pm 10^{\circ} \mathrm{C}$. The HTI equation was defined as:

$$
H T I=\frac{N O T \times \Sigma W F}{N O F}
$$

Where:

NOT - number of tears,

NOF - amount of casted samples,

$W F$ - weighting factor [4].

The value of the weighting factor depends on the nature and size of individual hot tears. Figure 6 shows the coefficient values for different types of hot tears.

The resulting HTI values can be characterized as a measure of susceptibility to tearing - the so-called "Hot Tears Susceptibility" (HTS). Five levels of severity were set for hot tearing that are identified by the following intervals:

$<0.5$ : minimal susceptibility,

$\mathbf{0 , 5}-\mathbf{1 . 2 5}$ : low susceptibility,

$1.25-2.25$ : moderate susceptibility,

2.25 - 3.5 : high susceptibility,

$>3.5$ : very high susceptibility. 


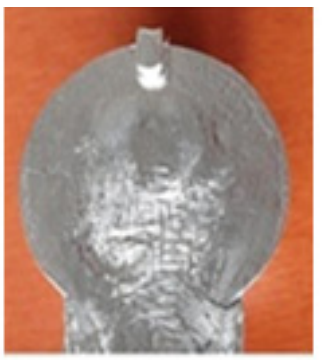

$\mathrm{WF}=0.25$

Moderate crack

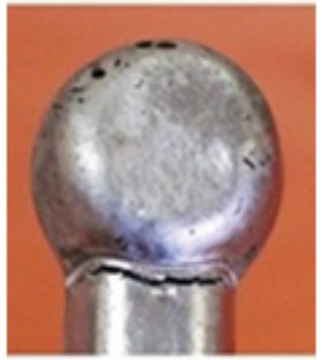

$\mathrm{WF}=0.75$

Large crack

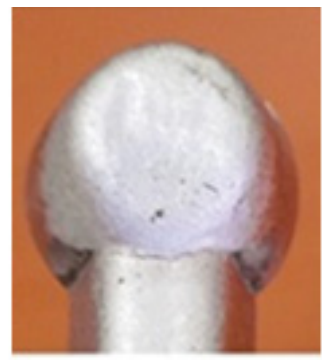

$\mathrm{WF}=0.5$

\section{Light cross section crack}

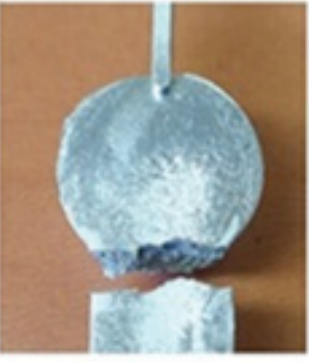

$\mathrm{WF}=1$

Separated arm
Fig. 6. Weighting factor categories

Each of the five rod lengths was given a rating value based on Fig. 6. The hot tears were classified into five levels of severity (from no tear $-\mathrm{WF}=0$, to complete separation $-\mathrm{WF}=1$ ). The overall hot tear rating was given as the summation of individual hot-tear rating of five bars - HTI. Based on HTI value, susceptibility (HTS) were estimated. From the above values it is clear that with increasing value of HTS, the tendency to hot tearing increases as well. Table 3 shows the results of quantitative evaluation together with details of casting parameters.

TABLE 3

HT index

\begin{tabular}{|c|c|c|c|c|}
\hline \hline Alloy & $\begin{array}{c}\text { Pouring } \\
\text { temperature } \\
{\left[{ }^{\circ} \mathbf{C}\right]}\end{array}$ & $\begin{array}{c}\text { Mold } \\
\text { temperature } \\
{\left[{ }^{\circ} \mathbf{C}\right]}\end{array}$ & HTI & HTS \\
\hline AlSi6Cu4 & $720 \pm 5$ & $150 \pm 10$ & 1,3 & $\begin{array}{c}\text { moderate } \\
\text { susceptibility }\end{array}$ \\
\hline AlCu4Ti & $720 \pm 5$ & $150 \pm 10$ & 3,7 & $\begin{array}{c}\text { high } \\
\text { susceptibility }\end{array}$ \\
\hline AlSi7Mg0.3 & $720 \pm 5$ & $150 \pm 10$ & 0,01 & $\begin{array}{c}\text { minimal } \\
\text { susceptibility }\end{array}$ \\
\hline
\end{tabular}

During the experimental works the casting parameters for each alloy were set to identical values in order to be able to compare the results achieved. The aim was to hold the processing parameters constant, so that any differences in the HTS were caused by different chemical composition of analyzed alloys. It is known from literature that the width of the solidification interval has a significant impact on the hot tearing formation. The wider the solidification interval, the greater is the alloy susceptibility to tearing. However for Al-Si-based alloys applies that exceeding a certain critical value of $\mathrm{Si}$ amount ( $5 \mathrm{wt} . \% \mathrm{Si}$ ), even though the interval of solidification is relatively wide, the content of the eutectic is sufficient enough to provide effective feeding and thereby it dramatically increases the ability to "heal" emerging hot tears - Fig. 7. Experimentally obtained graph [5] confirmed that, in the case of $\mathrm{Si}$, the width of the interval is not directly proportional to the HTS, and therefore also other factors must be taken into account, supporting hot tearing formation [5].

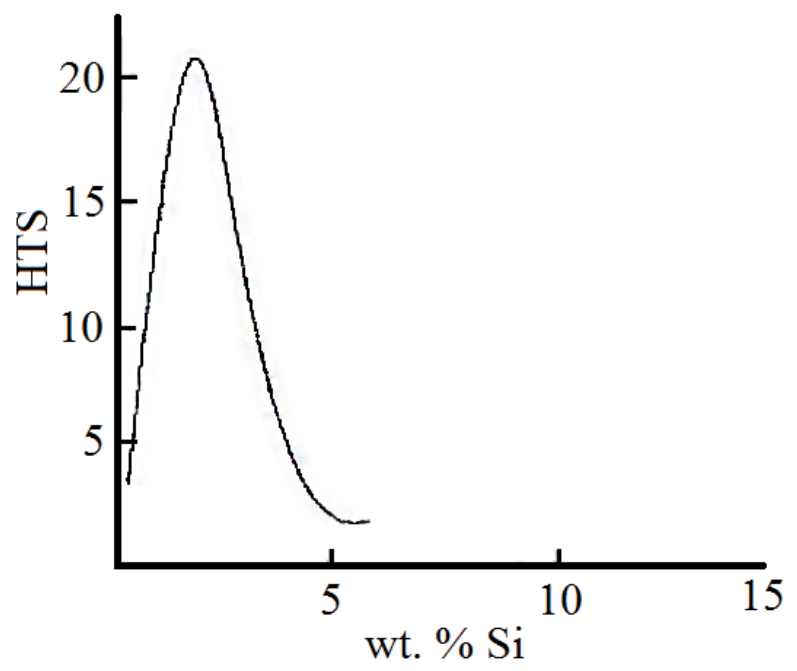

Fig. 7. Hot tears extension depending on Si amount [5]

In case of AlCu4Ti alloy evaluation (alloy with the widest solidification interval), the value of HTI was highest, the abovementioned argument seems to be correct in this case. Fig. 8 shows a cast sample with marked hot tear defects. Except the shortest arms, hot tears arose in all other arms. From the abovecharacterized scale of HTS values we can conclude that this alloy has a very high susceptibility to hot tearing.

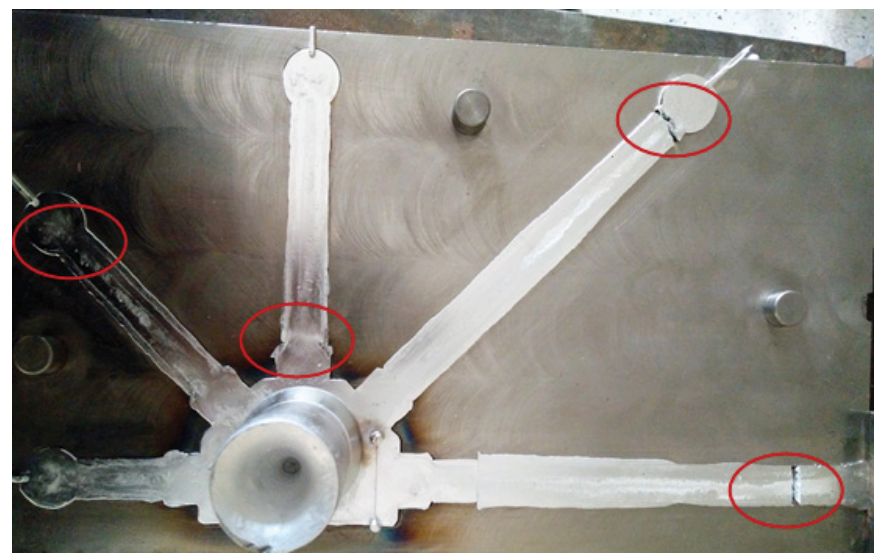

Fig. 8. Hot tears in AlCu4Ti alloys

Figure 9 can explain the reasons for high HTS values for the given alloy. The graph of experimentally obtained values points to the critical amount of copper in aluminium alloy, which causes hot tearing. Values of about $1 \mathrm{wt} . \%$ and also $4 \mathrm{wt} . \% \mathrm{Cu}$ represent critical amounts that increase HTS [6]. 


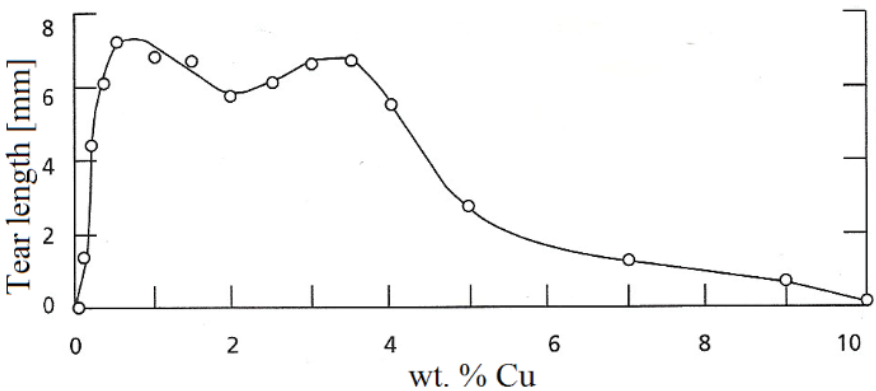

Fig. 9. Hot tears extension depending on $\mathrm{Cu}$ amount [6]

Experiments by Rosenberg and Flemings, or Clyne and Davies have confirmed that the addition of a certain quantity of $\mathrm{Ti}$ (ranging from about 0.15 to $0.2 \mathrm{wt} . \% \mathrm{Ti}$ ) can reduce hot tearing resistance, respectively can promote their nucleation. It can be concluded that the content of Ti in the critical amount $0.17 \mathrm{wt} . \%$ had a great impact on this alloy at high levels of HTS (in terms of chemical composition) [7].

The opposite situation occurs with alloy AlSi7Mg0.3 the value of HTS was very low (0.01). Thus, the material has minimum susceptibility to hot tearing. This is caused by the supercritical Si content, respectively by sufficient eutectic content that can compensate tears nucleation, as previously mentioned in Figure 8. Higher levels of Si also reduce linear shrinkage and tendency to microporosity [8].

During experiments, alloy AlSi6Cu4 reached HTI value of 1.3 , which means that the susceptibility is moderate. The silicon content is above the critical value, i.e. the amount of eutectic is able to compensate for any emerging hot tears. Increased susceptibility to cracking compared with alloy AlSi7Mg0.3 may be caused by the addition of copper, which allows increasing the strength by hardening through a phase of $\mathrm{Al} 2 \mathrm{Cu}$. However, $\mathrm{Cu}$ also greatly extends the solidification interval and thus supports the creation of hot tearing. Also, the amount of $0.2 \mathrm{wt} . \%$ Ti was in a narrow interval, in which Ti contributed significantly to the hot tearing susceptibility, but not to such extend as in $\mathrm{AlCu} 4 \mathrm{Ti}$ alloy (Fig. 10).

\section{Conclusion}

The main goal was to design, optimize and manufacture a new simple and reliable methodology to analyze hot tearing in aluminium alloy castings, and investigate the effect of chemical composition on the formation of hot tearing. The proposed methodology has proven to be reliable and repeatable. The number and nature of formed hot tears were evaluated by HTI index, respectively by the degree of susceptibility to hot tearing (HTS). The result of the initial experiment was to confirm the facts from the scientific literature, and to check the viability of the designed

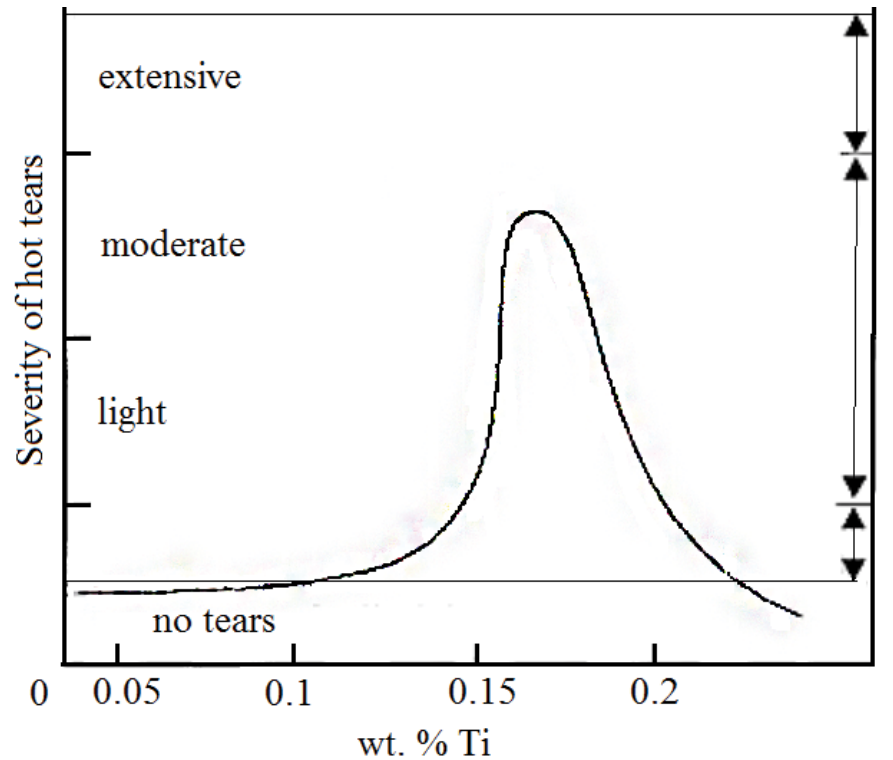

Fig. 10. Hot tears extension depending on Ti amount [7]

apparatus. Further work will focus on collecting data from the load cell during solidification, and monitoring hot tears evolution through refractory glass by a high speed camera, allowing hot tears to be evaluated in qualitative and quantitative terms.

\section{Acknowledgements}

This work was created in the framework of the grant project VEGA $\mathrm{N}^{\circ}$ $1 / 0363 / 13$. The authors acknowledge the grant agency for support.

\section{REFERENCES}

[1] R. Pastirčák, A. Sládek, Materials Engineering 10, 119-122 (2003).

[2] E. Krivoš, R. Pastirčák, R. Madaj, Archives of Metallurgy and Materials 59 (3), 1069-1072 (2014).

[3] T.W. Clyne, G.J. Davies, Metals Society, London, 275-78 (1979).

[4] D. Bolibruchová, M. Žihalová, Evaluation of vanadium influence in AlSi10MgMn alloy with increased iron level, Manufacturing technology: journal for science, research and production. - ISSN 1213-2489 16 (2), 471-475 (2016).

[5] Shan Lin, A Study of Hot Tearing in Wrought Aluminum alloys, "Universitè du Quebec - Chicoutimi (1999).

[6] D.G. Eskin, Suyitno, L. Katgerman: Progr. Mater. Sci. 49, 629-711 (2004).

[7] R.A. Rosenberg, M.C. Flemings, H.F. Taylor, Nonferrous Binary Alloys Hot Tearing, AFS Trans 69, 518-528.(1960).

[8] T.W. Clyne, G.J. Davies, A Quantitive Solidification Test for Casting and an Evaluation of Cracking in Aluminium-Magnesium Alloys, The British Foundrymen 68, 238-244 (1975). 